\title{
0 TRATAMENTO DA ESTOMATITE AFtóIDE RECORRENTE AINDA INTRIGA
}

A estomatite aftóide recorrente (EAR) é uma doença intrigante. Caracteriza-se pelo aparecimento de aftas bucais em períodos cíclicos, causando grande desconforto aos pacientes. É uma doença intrigante, porque, além de sua etiologia exata ser desconhecida (apesar das inúmeras hipóteses existentes, i.e associação com estresse emocional, hiperacidez bucal etc.), a terapêutica é quase sempre ineficaz (apesar das também inúmeras opções de tratamento).

A doença afeta cerca de $20 \%$ da população mundial e com maior frequência indivíduos do sexo feminino $0^{1}$. É considerada a mais comum das doenças que afetam a cavidade oral ${ }^{2}$. Existem três formas principais de apresentação de EAR, de acordo com o tamanho das aftas na cavidade bucal: as formas, major, minor e herpetiforme ${ }^{3}$. A forma minor se caracteriza pela presença de aftas arredondadas, de bordos regulares, com diâmetro variando de $3-10 \mathrm{~mm}$. Usualmente, acomete a mucosa nãoqueratinazada, únicas ou múltiplas. A forma major se caracteriza por apresentar úlceras extensas e dolorosas, com diâmetro maior que $10 \mathrm{~mm}$, demorando cerca de 4 a 6 semanas para cicatrizarem. A terceira forma (e a menos comum delas) de EAR é a chamada herpetiforme, que se caracteriza por aftas múltiplas (às vezes cerca de 100) e pequenas (menores que $3 \mathrm{~mm}$ ) distribuídas por toda a cavidade oral, podendo coalescer para formar úlceras maiores.

Quando se diz que a etiologia da EAR é desconhecida, isso não equivale afirmar que não existam hipóteses etiológicas com sustentação científica, e tampouco que uma hipótese não seja mais considerada que outras pelos especialistas no assunto. $\mathrm{Na}$ verdade, até onde se pode enxergar dentro do conhecimento científico atual, a causa básica do aparecimento da EAR encontra-se em um defeito da imunomodulação $0^{4,5}$. Sabe-se perfeitamente que existe nos tecidos da mucosa bucal, na fase ulcerativa da lesão, a presença de um grande infiltrado de linfócitos $\mathrm{T} \mathrm{CD8}{ }^{+}$. Além disso, há uma clara ligação da doença com fatores genéticos ${ }^{3}$.

No entanto, os estudos relacionados tanto à etiologia quanto à terapêutica da estomatite aftóide recorrente esbarram (e se tornam pouco confiáveis) muitas vezes na falta de critérios bem definidos de escolha da casuística (com os critérios de inclusão e exclusão necessários), ou na falta de controle adequado da medicação utilizada.

Inicialmente, deve-se frisar que, para se enquadrar na definição clínica de portador de EAR, o paciente deve apresentar aftas orais em períodos mínimos quinzenais (ou mensais), por mais de um ano de duração, com início do quadro na infância ou adolescência, sem que haja sinais de doença sistêmica associada (como por exemplo doença de Behcet ou doença celíaca) ${ }^{6}$

Muitos dos trabalhos que se propõem a testar medicamentos no tratamento e controle da EAR, ou pesquisar a etiologia da doença, não levam em conta essa definição clínica da doença.
Por ter etiologia incerta e terapêutica difícil, várias drogas (da vitamina B12 à talidomida, passando por agentes como a dapsona e o levamisole) já foram utilizadas no controle da doença, com inúmeros estudos publicados na literatura médi$\mathrm{ca}^{4,7,7,9}$. Muitos desses estudos não parecem bem controlados, colocando em xeque a validade de seus resultados.

A RAMB publica nesta edição um estudo acerca da utilização do levamisol no tratamento de estomatite aftóide do tipo minor. O estudo, duplo-cego, com utilização de controleplacebo é bastante rigoroso, inclusive nos critérios de inclusão dos pacientes estudados. Apesar da casuística pequena (14 pacientes no grupo de estudo e 10 pacientes no grupo controle) a conclusão, diferentemente daquela obtida por Glick \& Muzyka $\cdot{ }^{9}$, parece confirmar a ineficácia do levamisol no tratamento e controle da doença.

Entretanto, como doença intrigante que é, a estomatite aftóide recorrente ainda aguarda um grande ensaio clínico terapêutico (com controle-placebo), de preferência multicêntrico, que se proponha a comparar a eficácia das diversas drogas utilizadas no tratamento da doença, como a talidomida, a dapsona, o levamisol, os complexos vitamínicos e os corticosteróides.

Prof. Dr. Ivan Dieb Miziara Professor Livre-docente da Faculdade de Medicina da USP; médico chefe do grupo de Estomatologia da Divisão de Clínica ORL do HCFMUSP, São Paulo, SP

miz@uol.com.br

\section{Referências}

1.Casiglia JM. Recurrent aphthous stomatitis: Etiology, diagnosis, and treatment. General Dentistry 2002; 50(2):157-166.

2.Femiano F, MD, Lanza A,Buonaiuto C, Gombo F, Nunziata M, PiccoloS,Nicola C. Guidelines for Diagnosis and Management of AphthousStomatitisThe Pediatric Infectious Disease Journal 2007;• 26( 8):728-32.

3.Porter SR, Scully C, Pedersen A. Recurrent aphthous stomatitis. Crit Rev Oral Biol Med 1998; 9(3):306-21.

4.Volkov I, Rudoy I, Abu-Rabia U, Masalha T, Masalha R. Case report:recurrent aphthous stomatitis responds to vitamin B12 treatment. Can Fam Physician. 2005;51:844-845.

5.Boras VV, Lukac J , Brailo V, Picek P, Kordic D, Zilic IA. Salivary interleukin6 and tumor necrosis factor- in patients with recurrent aphthous ulceration. J Oral Pathol Med. 2006;35:241-243.

6.Scully C, Gorsky M, Lozada-Nur F. The diagnosis and management of recurrent aphthous stomatitis: a consensus approach. J Am Dent Assoc. 2003;134:200-207.

7.Shetty K. Thalidomide in the management of recurrent aphthous ulcerations in patients who are HIV-positive: a review and case reports. Spec Care Dentist. 2005;25:236-241.

8.Miziara ID, Miniti A, Gondim M. O uso da dapsona no tratamento da Estomatite Aftóide Recidivante. Rev Bras ORL 1992, 58(2):96-8.

9.Glick M, M uzyka BC. Alternative therapies for major aphthous ulcers in AIDS patients. J Am Dent Assoc 1992; 123: 61-5 